\title{
Can vernacular buildings survive with traditional life inside and tourism outside?
}

\author{
T. X. Zhang ${ }^{1}$, T. Yamamura ${ }^{2} \&$ Y. Fujiki ${ }^{2}$ \\ ${ }^{I}$ Peking University, China \\ ${ }^{2}$ Kyoto Saga University of Arts, Japan
}

\begin{abstract}
Tourism has positive as well as negative effects on the sustainable utilization of traditional vernacular buildings, especially in cultural heritage cities that have become important tourism destinations. Many of these cities improve the accommodation facilities by utilizing traditional vernacular buildings, while consequently meaning that these cultural heritages are in danger of losing their authenticity. On the other hand, tourism development also has positive effects in that it brings in funds that help restore and renovate the buildings which would otherwise face gradual deterioration. This is a dilemma that many historical cities face under tourism development, especially in developing countries. The authors categorize the development approach of cultural heritage tourism into two patterns. One is the "outside-in" approach, which means to dominantly satisfy the tourists' needs while sacrificing the local cultural character. The other approach is the "inside-out" approach, which means that the local community follows its own growth principle, and tourists come in mostly to enjoy and to learn from the local wisdom. We examine the two approaches by taking the current status of protected buildings in Lijiang city as a case study. In this famous Chinese world heritage city, some 140 important vernacular buildings face serious pressure of tourism oriented transformation both in form and in usage. We investigate the buildings and find they have changed their usage dramatically, accompanied with relevant changes in form, layout, and decoration styles. We further review the policy system and find that these changes in vernacular buildings are due to lack of proper standing in conservation policy system, lack of sufficient financial aid, and lack of full technical support.
\end{abstract}

Keywords: tourism, vernacular building, inside-out approach. 


\section{Introduction}

Cultural heritage tourism is swiftly growing in developing countries like China. In 2005, foreign tourists have reached 120.29 million, and foreign tourism income reached 29.2 billion US dollars. Domestic tourists reached 1.2 billion, and domestic tourism income reached 528.6 billion RMB. The total tourism income reached 768.6 billion RMB [1]. A large amount of these tourists and income flowed into historical towns and traditional villages. These old towns and villages have consequently seen outstanding transformations both in physical and social aspects, among which the loss of traditional townscape character and local community connection are two of the commonly mentioned issues. Many vernacular buildings can not keep being inhabited as local people's houses, but instead have been rented, sold, and in most cases transformed into tourism facilities such as shops, restaurants, hotels and museums. These functional changes have unavoidably caused changes in layout, forms and collective townscape images. They also connect to the loss of community sense due to the outflow of local inhabitants for economic or social reasons.

In this paper, we examine the functional transformation of traditional vernacular buildings in cultural heritage sites and suggest that they connect closely with tourism development patterns. Up till now, most tourism patterns in cultural heritage sites can be concluded as either "tourism-oriented" or "outsiderdominated", which means that the tourists' needs dominate the transformation process, showing an "outside-in" approach. The result is on the one hand the increase of tourism-oriented facilities, while on the other hand the loss of traditional life style, local community and traditional vernacular buildings. Most famous tourism destinations, however, are forced by the market to follow this approach in the past decades.

We hereby discuss the possibility of a reversed "inside-out" pattern as an alternative tourism development approach for the cultural heritage sites. By this we mean that the local people, together with their traditional buildings and life styles, could nevertheless become tourism destinations, and therefore their consistent inhabitation could satisfy the demand of both tourism and local community development [2].

There are many factors that contribute to the inside-out approach, among which housing is one of the most important. In this aspect, traditional vernacular houses have bilateral functions: they are on the one hand a life world for the local people to reside, and on the other hand an absorbing tourism resource for the tourists to explore. Therefore, they are an important intermediate tool to mediate between the insiders and the outsiders. It is thus very important to conserve the traditional vernacular buildings against the trend of tourism development $[3,4]$.

Factors that influence the conservation of local vernacular buildings include the owner, user, renter, usage, value, location, etc. Among these, usage consistency is a key issue by which we can determine to what extent the houses are likely to be preserved or changed. A common phenomenon is that the more local inhabitants keep living in these houses, the more likely the houses could be 
preserved. On the contrary, when the houses change their functions, owners or users, they are more likely to be greatly transformed either in layout or in form. Therefore, lack of usage consistency is likely to be the key element that threatens sustainable tourism development.

\section{Methodology}

In this paper, we take the old town of Lijiang City - a world cultural heritage site in Yunnan province, China - as a case study to illustrate the actual situation faced by vernacular buildings in cultural heritages sites. We selected Lijiang City because it is 1) a world heritage city whose vernacular building groups are of great value; 2) a multi-ethnic city mixed with Naxi people and other minority people; 3) a heavily tourism-oriented destination.

In order to clarify the functional transformation of Lijiang's vernacular buildings, we choose PVBs (Protected Vernacular Buildings designated by the Lijiang government) as the investigation targets. PVBs are important indicators of social and physical change in Lijiang city from 1997 to 2005. Unlike most other buildings that lack of accomplished documents, almost every PVB was investigated and documented by scholars in 1997, which makes it possible to compare their past status with the present.

We use multi-factor method to analyze the change of PVBs' functions. The factors include: house types, preservation status, location, change of owners, renters, and the users. We try to find out how these factors link with each other and how they contribute to the functional change of PVBs. We assume that when the usage, user and owner factors correspond to each other, the buildings have higher possibility to be used appropriately. We determine the change of form according to the appearance factors that include building style, decoration motif, color, material, etc.

Site investigations and interviews are the basic research methods. We confirm the existence of every PVB according their address and record their current status one by one. We use the temporal analysis to compare the data between 1997 and 2005. 1997 was the year when PVBs were first designated, and the year when the Old Town of Lijiang was listed as a World Cultural Heritage site. It was also the year when tourism began to boom. The year 2005 was a time when eight years of tourism booming has shown both positive and passive effects in many aspects.

\section{PVBs in Lijiang city and Xinyijie Community}

\subsection{PVBs in Lijiang}

In 1997, Lijiang County designated 140 PVBs, including 52 IPVBs (Important Protected Vernacular Buildings) and 88 CPVBs (Common Protected Vernacular Buildings). They are located in three areas: the Old Town area, the Baisha area, 
and the Shuhe area. Among them, the Old Town area is the main site of World cultural heritage. There are 7 communities in this area, the number of IPVBs and CPVBs in these communities are shown in Table 1.

Table 1: $\quad$ PVBs in different areas of Lijiang.

\begin{tabular}{|c|c|c|c|c|}
\hline Area & Community & IPVB & CPVB & Total \\
\hline Old town & Xinyijie & 7 & 15 & 22 \\
\cline { 2 - 5 } & Xinhuajie & 12 & 10 & 22 \\
\cline { 2 - 5 } & Guangyijie & 10 & 10 & 20 \\
\cline { 2 - 5 } & Yishang & 2 & 2 & 4 \\
\cline { 2 - 5 } & Wuyijie & 5 & 20 & 25 \\
\cline { 2 - 5 } & Qiyijie & 10 & 9 & 19 \\
\cline { 2 - 5 } & Subtotal & 46 & 66 & 112 \\
\hline \multicolumn{7}{|c|}{ Baisha } & 3 & 9 & 12 \\
\hline \multicolumn{2}{|c|}{ Shuhe } & 3 & 13 & 16 \\
\hline \multicolumn{2}{|c|}{ Total } & $\mathbf{5 2}$ & $\mathbf{8 8}$ & $\mathbf{1 4 0}$ \\
\hline
\end{tabular}

Note: $\quad$ PVB=Protected Vernacular Building; IPVB=Important Protected Vernacular Building; $\mathrm{CPVB}=\mathrm{Common}$ Protected Vernacular Building

\subsection{Distribution of PVBs in Xinyijie Community}

In this paper, we do in-depth investigation for PVBs that locate in the Xinyijie Community area, Figure 1. It has 507 registered households (1,578 inhabitants), however, only 169 households (600 people) actually reside there, and the other 338 households have moved to other places. In comparison with the registered inhabitants, the temporal residents count to 400 households (1,200 people). This phenomenon is typical in the Old Town of Lijiang city, and it brings great changes in PVBs. Therefore, the change of PVBs in this community can reflect the status of other communities throughout the city. It is important also because it covers both the main entrance area and the central commercial area, including the famous Sifangjie Square, Figure 2.
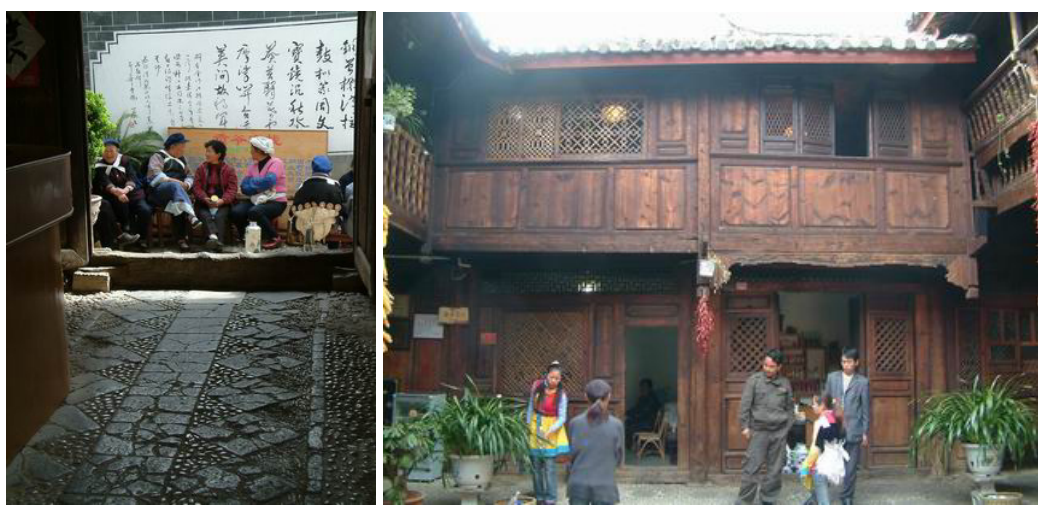

Figure 1: $\quad$ PVB used 1) by tourists and inhabitants; 2) as tea house. 
Xinyijie Community is a typical local community that occupies an average PVB number. There are totally 22 PVBs in Xinyijie community, among which 7 are IPVBs and 15 are CPVBs.

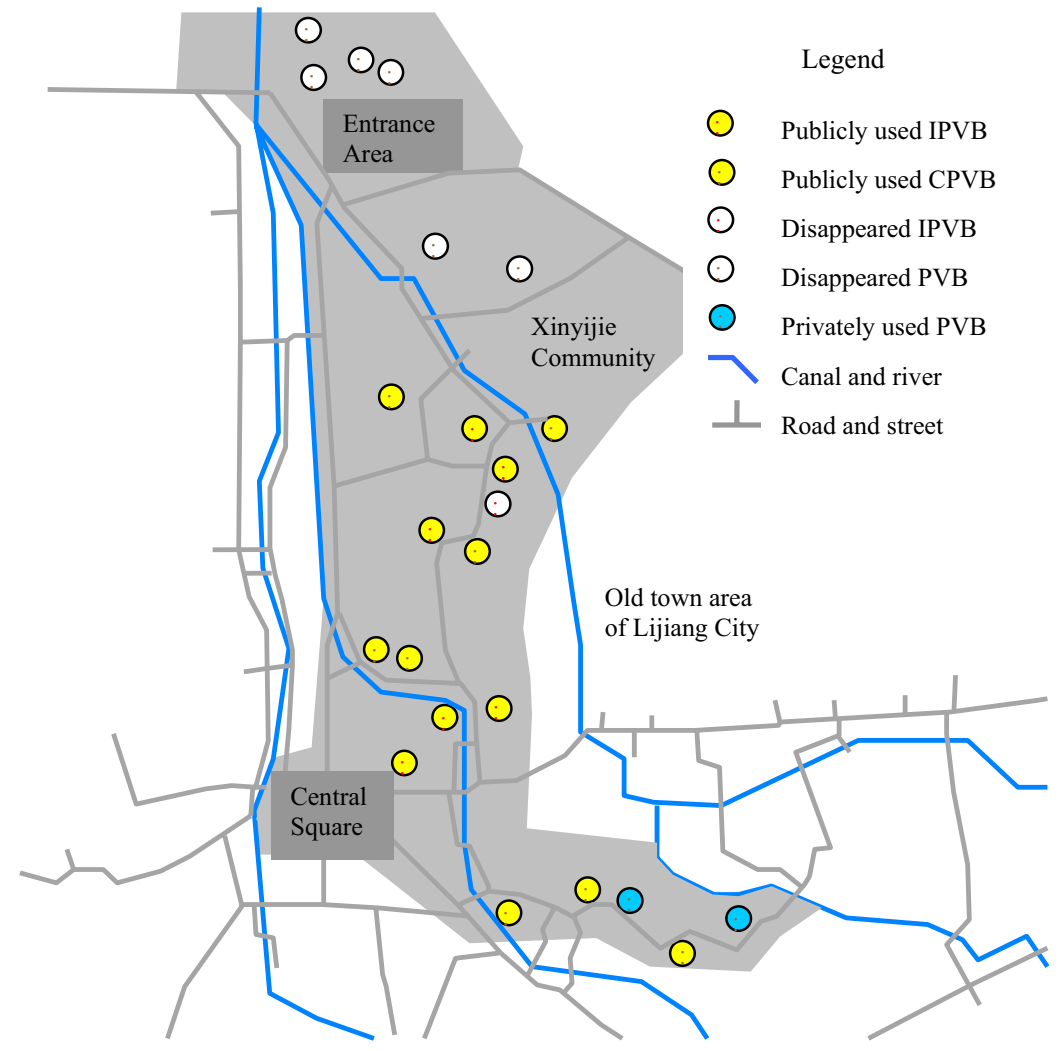

Figure 2: Distribution of PVBs in Xinyijie Community, Lijiang City.

\subsection{Current status of PVBs in Xinyijie Community}

We investigated the PVBs of Xinyijie Community in 2005-2006, and found that among 22 PVBs, 7 disappeared despite of the protection policies, among which 1 is IPVB and 6 are CPVBs. While 19 PVBs were originally used as local people's houses in 1997, only 2 still remains to be so in 2005, and the other 13 have been transformed to tourism related facilities, Table 2 .

We further categorize the usages into privately used, publicly used, and tourism related facilities. We find that tourism related facilities occupy the largest amount, and among them guest house is the most preferred type. Within the 10 tourism related facilities, 4 are used as guest houses, 1 as bar, 3 as 
restaurants, 1 as exhibition, and 2 as hotels. Among the 3 publicly used houses, 2 are offices, 1 is local hospital. The privately used houses are divided as 1 for local inhabitants and 1 for rent, Table 3.

Table 2: $\quad$ Current status of PVBs in Xinyijie Community, Lijiang City.

\begin{tabular}{|l|l|l|l|l|}
\hline Type & Location (\#) & Age & Usage in 1997 & Usage in 2005 \\
\hline IPVB & JSX 21\# & Before 1949 & House & Guest house \\
\cline { 2 - 5 } & JSX 34\# & 1900 yr ago & House & Guest house \\
\cline { 2 - 5 } & MSX 47\# & Before 1949 & Hotel & Disappear \\
\cline { 2 - 5 } & MSX 53\# & Before 1949 & House & Bar, tea house \\
\cline { 2 - 5 } & MSX 14 & 200yr ago & House & Guest house \\
\cline { 2 - 5 } & SFJ 1\# & Before 1949 & House & Restaurant \\
\cline { 2 - 5 } & SFJ 17\# & Before 1949 & House & Restaurant \\
\hline CPVB & JSX 106\# & 1930 s & House & Disappear \\
\cline { 2 - 5 } & JSX 105\# & 1930 s & House & Disappear \\
\cline { 2 - 5 } & JSX 101\# & 50 yr ago & House & Disappear \\
\cline { 2 - 5 } & JSX 85\# & Before 1949 & House & Disappear \\
\cline { 2 - 5 } & JSX 63\# & Unknown & House & Office \\
\cline { 2 - 5 } & JSX 4\# & Before 1949 & Hotel & Hotel \\
\cline { 2 - 5 } & JSX 25\# & Before 1949 & House & Disappear \\
\cline { 2 - 5 } & MSX 48\# & Before 1949 & Hotel & Disappear \\
\cline { 2 - 5 } & MSX 43\# & Before 1949 & Office & Hotel \\
\cline { 2 - 5 } & MSX 74\# & $1930 s$ & Music hall & Hospital \\
\cline { 2 - 5 } & MSX 78\# & $1900 s$ & House & Guest house \\
\cline { 2 - 5 } & BSF 33\# & Before 1949 & Photo shop & Office \\
\cline { 2 - 5 } & BSF 35\# & $1930 s$ & House & House \\
\cline { 2 - 5 } & BSF 56\# & Before 1949 & House & Exhibition \\
\cline { 2 - 5 } & BSF 50\# & Before 1949 & House & House \\
\hline
\end{tabular}

Note: JSX=Jishixiang street; $\quad$ MSX=Mishixiang $\quad$ street; $\quad$ SFJ=Sifangjie $\quad$ street; $\mathrm{BSF}=$ Baisuifang street.

Table 3: $\quad$ PVB usage type division.

\begin{tabular}{|c|c|c|c|c|}
\hline & & IPVB & CPVB & Total \\
\hline Private & Local owner & 0 & 1 & 1 \\
\cline { 2 - 5 } & Rent & 0 & 1 & 1 \\
\cline { 2 - 5 } & Subtotal & 0 & 2 & 2 \\
\hline \multirow{4}{*}{ Public } & Office & 0 & 2 & 2 \\
\cline { 2 - 5 } & Hospital & 0 & 1 & 1 \\
\cline { 2 - 5 } & Subtotal & 0 & 3 & 3 \\
\hline \multirow{4}{*}{ Tourism } & Guest House & 3 & 1 & 4 \\
\cline { 2 - 5 } & Bar & 1 & 0 & 1 \\
\cline { 2 - 5 } & Restaurant & 2 & 0 & 2 \\
\cline { 2 - 5 } & Exhibition & 0 & 1 & 1 \\
\cline { 2 - 5 } & Hotel & 0 & 2 & 2 \\
\cline { 2 - 5 } & Subtotal & 6 & 6 & $\mathbf{2 2}$ \\
\hline \multicolumn{2}{|c|}{ Disappear } & 1 & $\mathbf{1 5}$ & 10 \\
\hline
\end{tabular}




\section{Functional change analysis}

\subsection{Effects of functional change}

Different usages of PVBs result in different conservation status respectively.

PVBs that are used as local people's private houses are more likely to keep their original style. Because the PVBs were originally designed as houses, the layout and style need not be restructured to a great extent if they keep the original function. The local inhabitants are also willing to keep the traditional style as their inherited properties.

Publicly used PVBs are more likely to be renovated to fit new functions. For example, a PVB has been used as a hospital, and has been painted white to show its function, but white is a color that was never used in local vernacular buildings, Figure 3.

As PVBs were originally used as private houses, they do not fit for tourism usages like hotels, restaurants, etc. Consequently, tourism oriented renovation often leads to misuse of PVBs.

PVBs used as restaurants are the most likely to be transformed both in forms and in layout. The need for bigger interior space, kitchen and other storage rooms make the transformation unavoidable.

PVBs used as bars tend to be given a new style that is clearly different from the typical vernacular building styles. The houses are often decorated with remote and minority style, having no necessary relationships with the traditional vernacular buildings within the city context.

Those used as guest houses are often restructured for allowing two-bed rooms, bathrooms and other modern tourism facilities to be built within the PVBs. The interior would therefore see a big change in style, color, material, etc.
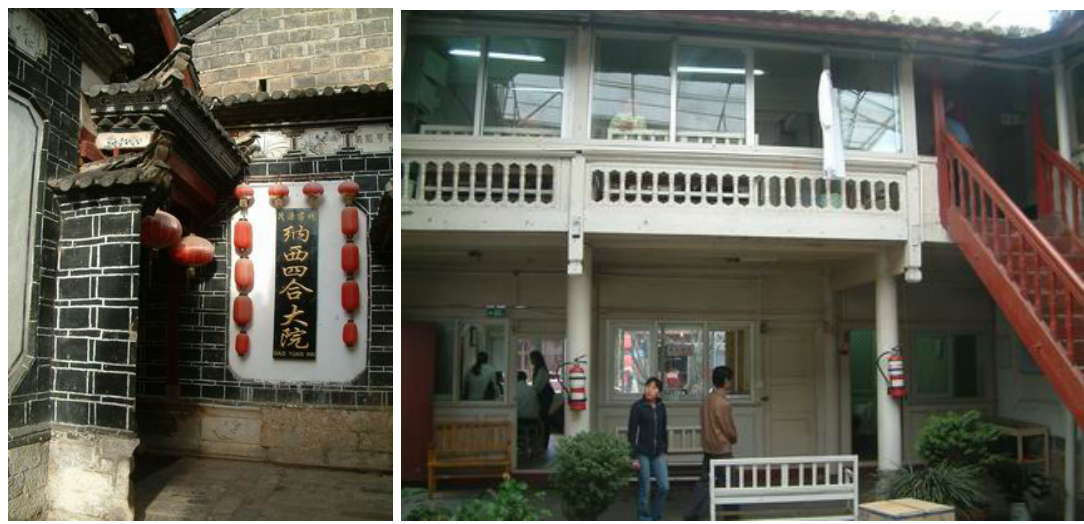

Figure 3: $\quad$ PVB used 1) as guest house; 2) as local hospital.

\subsection{Factors that affect the usage}

Factors that affect the usage transformation include location, value, owner and user, etc. 
The PVBs that are still used as houses are located backward from the central area of tourism. In comparison, the PVBs in central tourism areas are more likely to be rented and therefore it is common to see their functions and forms changed.

The disappeared PVBs mostly locate in the entrance area of the city, where large scale developments such as luxury hotels and parking lots were built. This shows that big tourism facilities are controversial in cultural heritage cities in that they could greatly change the urban tissue and townscape.

The guest houses are mostly transformed from IPVBs (3 out of 4 ). This shows that people like to use more delicate and traditional houses to attract tourists. Therefore, the IPVBs become the main target for the developers to buy or rent. The result is, despite they are listed as IPVBs, it is very difficult for the owners to refuse the allure of high rent fee, and therefore the preservation can not be fully realized, Figure 4.

When a building's property owner right belongs to the government, it is more likely to be demolished in favor of big developments like parking lots or hotels. This may happen because the government can use these houses to support and pursue the economic goal.

If the owner were the local people, it would be easier to conserve because the owner knows on how to utilize the house in its traditional way. But when the house is rented, the renter does not necessarily follow the traditional building principles despite of all the restriction rules. Many outsider owners would bring modern art or remote cultural atmosphere to the house, while in most cases these do not fit into the cultural heritage context properly.

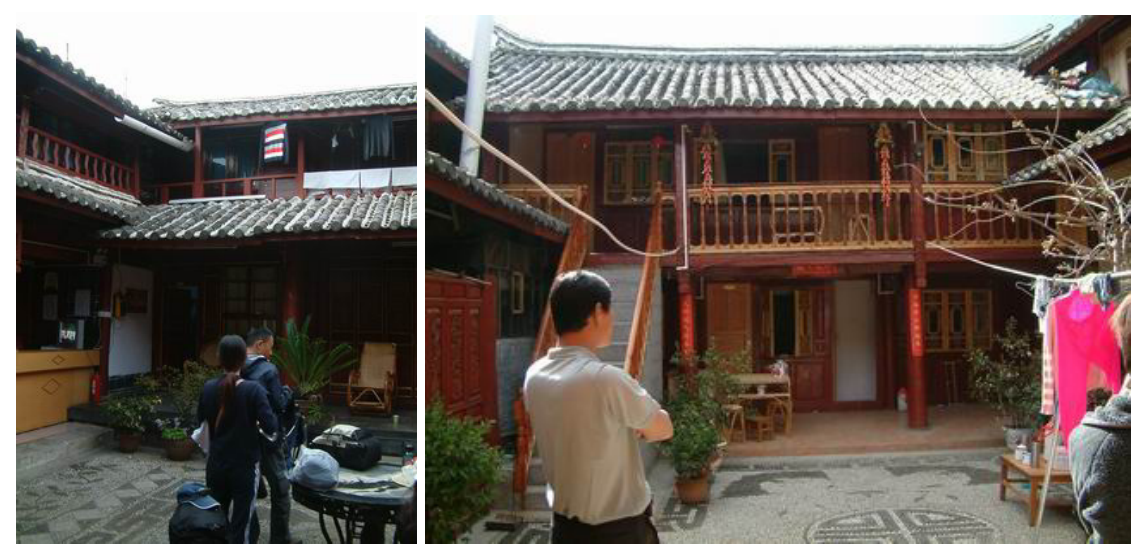

Figure 4: Courtyard of PVB used as guest houses.

\subsection{Policy support}

The current situation of PVBs connects directly with the overall management policy of the local government, which was termed "Lijiang Model" in 2000. "Lijiang model" refers to the cultural heritage management system that integrates 
the government, the funding corporation, and the local inhabitants to improve tourism development as well as heritage conservation. The Lijiang Old Town Administration has initiated such campaigns like civic facility construction, old town management fee collection, inhabitant benefit policy, etc. Organizations such as the Old Town management company were also set up to fulfill the management demands, and the guideline for house restoration was also accomplished in 2006.

To conserve the houses in their original style is a highly money consuming and sophisticated issue. Even if the PVBs are used by the local inhabitants, they obviously lack the finance or techniques to renovate the PVBs by themselves. Consequently, following the growth of their family members, when they have to renovate the house, they would prefer to simplify the original style in order to lower the price. Or, under the pressure of tourism development, they might simply rent the house for the sake of higher income. Therefore, only by keeping the local inhabitants cannot guarantee good maintenance for PVBs.

There are two approaches that the local people could get financial subsidize in renovating their house. One is the fund offered jointly by the government and a foreign foundation organization, through which the inhabitants can receive up to $20,000 \mathrm{RMB}$, or an average of $10,000 \mathrm{RMB}$ for the purpose of house renovating, as long as their renovation plan is proved by the government. But this amount is obviously insufficient, and the local inhabitants would have to pay for the other part if the fee exceeds the amount, which is usually the case.

In this aspect, those PVBs that are owned and managed by big-hand companies or government show their advantage in having better finance for maintenance. However, in this case, two problems might occur: 1) the PVBs would usually be renovated in such an exaggerated way that the local vernacular motifs are lost; 2) the PVBs are used totally as tourism facilities, and therefore lack the living atmosphere of the local community.

The reason why local life in PVBs is important is nonetheless an arguable issue. An ideal status is that all the PVB keep housing the local people and act as "Noah's Ark" to carry on the traditional life along with the physical setting of the housing. This is like an unrealistic dream, but it is a dream that could be made real by collaborative efforts of both the government and the local people.

The Lijiang local government began to recognize the importance of keeping the local people and their life. In 2003, the government issued a "Local-resident beneficial policy", by which the local people who have been living in the old town for more than 10 years could get a 10RMB incentive by the government. This policy intends to remain as many local people in the old town as possible, and it does earn many positive responds from the residents. Nevertheless, an incentive of $10 \mathrm{RMB} / \mathrm{month}$ can in no way compare with a rent of 2,000RMB/month. Therefore, it cannot effectively stop the trend that the local people move out of the old town and leave their house rented and modified by outsiders. In this way, the local communities are difficult to keep on; instead they become greatly mixed by outsiders. The local senses of belonging, self recognition, and self esteem have mostly been lost. 


\section{Conclusion}

In tourism development, the vernacular buildings keep changing in forms, function and cultural meanings. They are used both as the real life world for the local people, and as a tool to attract the tourists at certain stage. While in most cases they tend to transform to fit the tourists' needs, this trend need to be carefully controlled so that it would not hamper the local life in the long run.

Along with cultural heritage tourism development, many local inhabitants are forced to open up to the outside world, and subsequently lose their physical settings as well as social networks in which they were grown up. In extreme cases, the whole tourism site would face the danger of being overturned, and the local inhabitants would no longer be the actual owners any more. The problem is that these sites would experience a deteriorating process in its life-cycle once tourism slows down, and the real loser would ultimately be the local inhabitants.

Without the local inhabitants and their traditional life style, cultural heritage sites would lose their authenticity and attractiveness. Sustainable tourism in cultural heritage sites not only refers to the physical form, but also to life style, value, belief, accustom, etc. To ensure such an overall conservational demand, the "inside-out" pattern should be taken into account so as to benefit the local community in the first place and the tourists in the second. Because the insideout pattern does not seem to follow the basic cost-benefit principle in economics, it not only needs positive contribution of the inhabitants, but also needs sufficient financial and policy support from the government.

The usage consistency plays an important role for sustainable usage of traditional vernacular buildings in cultural heritage sites. Keeping the usage consistency can be seen as a mingle of participatory design in urban planning field, and a kind of "self-initiated" tourism development in which local life could persist and be enjoyed by both local people and tourists.

\section{References}

[1] China Tourism, http://www.cnta.gov.cn/

[2] Jiang, G., (ed.). Lijiang: the Beautiful Naxi Homeland, China Architecture \& Building Press: Beijing, 1997.

[3] Zhang T.X. Yamamura T., Fujiki Y. Conserving the Comprehensive Image of Natural Settings for World Heritage Sites, 15th General Assembly and Scientific Symposium of ICOMOS. Xi'an, China, 2005.

[4] Zhang T.X. Yamamura T., The Spatial Structure of Urban Spaces in Lijiang City, Acta Scientiarum Naturalium Universitatis Pekinensis, Vol.39, No.4, 467-473, 2003. 